\title{
Tax Avoidance in Pakistan: Drivers and Necessary Policy Interventions
}

\author{
* Dr. Sikandar Hussain Soomro, Assistant Professor \\ ** Roshan Ali Umrani, Lecturer \\ *** Dr. Imdad Ali Khowaja, Assistant Professor
}

\begin{abstract}
Tax avoidance in Pakistan is extremely high, prompting a weakening in the monetary circumstance and an absence of arrangement of open administrations. The report breaks down four factors of expense resolve: sentiments of blame and disgrace; absence of trust in the administration; discernment about different residents who make good on assessments; and levels of set approvals, as factors of tax avoidance in the Republic of Pakistan. The work incorporates a review led through a poll disseminated among a deliberately chosen test of 400 salaried representatives to gather reactions that were dissected utilizing the t-test. The discoveries propose that the view of the utilization of cash, the components of disgrace, the impression of the consistent conduct of different residents, and the degree of authorizations influence tax avoidance. In any case, the factors of blame and view of defilement don't significantly affect shirking conduct. Some strategy mediation's to control the danger of tax avoidance have been proposed toward the finish of the archive. These approaches incorporate persuading citizens through strategies, for example, selling, forcing fines and punishments, and distributing the names of defaulters through the media and the duty office site.
\end{abstract}

Keywords: $\quad$ Tax evasion, Tax Determination, Taxation, Pakistan, Communal Policies

\section{Introduction}

Expenses assume a significant job in the monetary advancement of the nation since they permit the legislature to accomplish its targets, for example, barrier, instruction, equity, and social government assistance for its residents (Awan \& Hannan, 2014). Assessments likewise permit the administration to spare itself from unfamiliar reliance and bolster its business by burdening ingresses. The significance charges in trendy nations like the Republic of Pakistan remain massive since more than $90 \%$ of the salary created originates from charges. As per the Ministry of Finance of the Management of Pakistan, the expense assembly of Pakistan is separated hooked on to dual general classifications:

\section{Direct Taxes}

These assessments are additionally partitioned into:

a. Income Tax

b. Workers Welfare Fund

c. Capital Value Tax

2. Indirect Taxes

a. Sales Tax

b. Customs Duty

c. Federal Excise Duty

The Resolution of Pakistan expresses that the Republic of Pakistan is a league by 04 regions. The State Administration produces (95\%) of all-out expenses, although the commonplace offer is fair (5\%) of all-out income assortment. Government interest is additionally isolated among the areas as indicated by specific standards set up in Editorial Legal Orders 160 (1) of the nation's resolution and amendments.

Pakistan is a nation that takes a duty to G.D.P proportion of a mere thirteen percent which-as is the most reduced of the developing economies (SDPI, 2013). Pakistan has confronted the difficulty of helpless duty assortment. An examination directed by the World Bank in 2009 expressed that the nation's financial hole was 79\%, qualifying it as one of the most minimal on the planet (World Bank,

* Department of Economics University of Sindh, Jamshoro Email: sikandar@ usindh.edu.pk

** Shahdadkot Campus, Shah Abdul Latif University, Khairpur Email: umrani.roshan4010@ gmail.com

***Department of Economics, University of Sindh, Jamshoro Email: imdadalikhowaja@gmail.com 
2009). The IMF in its 2015 report1 expressed that Pakistan's expense to-GDP proportion was just $11 \%$, while just $16 \%$ of potential citizens were remembered for the nation's assessment base. The outcomes of such a helpless gather are numerous folds. To start with, this decreases income assortment, as the administration, to improve income, needs to decide on more backhanded expenses that are backward (Zafar, 2017). This circumstance thusly builds by and large costs in the nation and the overall population endure subsequently.

One of the primary purposes of the helpless assessment assortment in Pakistan is tax avoidance. Tax avoidance is a proper articulation of duty robbery and incorporates each one of those exercises of covering of salary or misrepresentation of costs that lead to the hardship of expense incomes from the specialists (Azhar, 1996). It is not quite the same as tax avoidance as avoidance includes lawful manners to lessen the taxation rate (p. 656). The topic of tax avoidance isn't different from Pakistan. Duty avoidance and the subversive economy occurred at the national level during the 1970s (Aslaams, 1997). Be that as it may, the circumstance compounded after some time.

Tax avoidance in the nation expanded after some time. Complete tax avoidance in Pakistan is assessed at 1.5 billion PKR in 1973, which expanded to 152 billion PKR in 1996 (P.I.D.E, 1997). In 2012, the (N.A.B), a defilement guard dog in the nation, evaluated the loss of government income to the nationwide reservoir at PKR 7.0 million every daytime, with tax avoidance as the major primary driver (Dawnn, 2012)...

The primary goal of the article is to know the factors of tax avoidance inside the Republic of Pakistan that-has had such-as monetary and communal ramifications intended for the nation. Discoveries of the archive will be supportive as it will permit the legislature to assume responsibility for monetary circumstances \& lessen unfamiliar reliance.

\section{Objectives of the Study}

1. On the off chance that the sentiment of blame and disgrace prompts tax avoidance in the nation.

2. On the off chance that the impression of the different citizenry who pay charges influences tax avoidance conduct.

3. If the absence of trust in the government prompts tax avoidance.

4. If the degree of punishments for avoidance influences tax avoidance.

\section{Review of Literature}

The writing has given various implications and meanings of tax avoidance. As per (Chiumya, 2006) tax avoidance alludes to the disguise of salary and benefits; overhead costs; and distorting wellsprings of pay. Akrem, Ilyes and Moebin, (2016) insists that duty avoidance is viewed as an unlawful activity an infringement of the law since it includes the purposeful disguise of realities identified with salary acquired through legitimate foundations (Ghafor \& Hanan, 2015) calls toll avoidance as-if worldwide wonder over wins wherever without qualification of religion or customs and goes connected at the hip with the duty procedure.

Others have named the absence of trust in government and state organizations and the utilization of their duty cash by the party-political and administrative world-class as a deciding variable of levy avoidance (Saad, 2003), (Saam, 2011) and Torgleer (2002) through (Ajaaz \& Ahmad, 2011) and (Syadulleh, 2014) grouped debasement, terrible administration, and political shakiness as liable for offering ascend to tax avoidance practices among individuals. While the writing additionally asserts that individuals cling to propensities for tax avoidance on the off chance that they reflect that the administrations gave to them are noten adequate or else the majority are denied of their-as privilege and entree to open administrations (Kamal, 2005).

Higher expense rates and the out of line charge framework are likewise a reason for concern with regards to the relationship with tax avoidance. A significant part of the scholastic effort has recognized a confident connection among advanced duty taxes and an unreasonable assessment framework with rates avoidance in the economic sector. As per (wadhwaa \& Pall, 2001) higher expense rates and various assessments on a lower charge base has been a deciding component of helpless duty assortment. Khann and Ahmad, (2013) expressed that once assessment taxes are advanced and individuals see that-the advantages in reoccurrence for the charges waged are not all that many, they abstain from making good on charges and, along these lines, stay away from charges. The most elevated direct assessment rate in the economy prompts a casual or underground economy, as individuals decide on casual and undocumented exchanges to keep away from their pay being 
burdened through the specialists Salmans Aslams (1999).

Convinced individual attributes were recognized as factors of tax avoidance. As indicated by (Slemrod, 2007) wedded men avoid more contrasted with ladies and single individuals, while the youthful sidestep more than the old. (Richardson, 2006) demonstrated sexual orientation, age, instructive level, and wellspring of pay, among different factors, as contributing elements or causes of tax avoidance that take a noteworthy association with duty avoidance.

The writing had additionally brought up different factors that add to tax avoidance. A significant determinant that prompts tax avoidance included dread of discipline and punishments for tax avoidance and had an immediate and positional relationship (Sandmo 2004). As indicated by certain researchers, individuals sidestep charges on the off chance that they consider that others are additionally doing likewise Uslaner (2003). Individuals sidestep a lot of assessments at whatever point they see that this training is completed by individuals in their neighborhood or regardless of whether they accept that such practice is happening in the nation in general (Hanousek \& Palda, 2004).

Tax avoidance is a worldwide wonder that has existed on the planet and Pakistan is no exemption. The writing recommends that debasement, absence of exchange transparency, low per capita pay, and absence of political solidness are a portion of the reasons for helpless assessment assortment as to the nation (Ameen, Nadeem, Parven, Kamren \& Anwer, 2013). On the other likewise, recommend fundamental driver helpless assessment assortment in Pakistan incorporate helpless expense base, dependence on charge excluded divisions (the agrarian segment), absence of information about the duty framework and unfamiliar guide (Chaudhry \& Munir, December 2010).

A few researchers accept that political elites are the primary driver of infusing charge sly conduct among the majority. As per (Bukhari \& Haq, 2014) the assessment specialists are not enabled to uphold their controls over the rich and tip-top of the nation who escape by utilizing their individual party-political and monetary forces. Besides, this exclusive class connection in their structures as it appreciates the solaces and points of interest of open cash. An investigation led on the nation's parliamentarians expressed that solitary $02 \%$ of them ensured their NTNs while just a 10th as it settled their expenses (C.P.D.I \& C.I.R.P, 2010).

The writing takes accentuated out of line and higher assessment rates, backward duty framework, botch, debasement, and absence of trust in the administration as the fundamental driver of tax avoidance in Pakistan (Awan \& Hannan, 2013) and (Khann \& Ahmad, 2013). Because of advanced assessment taxes and gigantic consistence prices, individually enjoyed the surreptitious exercises and along these lines, the legislature is denied of income age (Feltenstein \& Cyan, 2013).

Thusly, the administration, to create more income, decides on wasteful expense plots that further lead to tax avoidance and the endless loop proceeds (Besst, Brockmayer, Klaven, Spinnawijn, \& Wasem, 2014). What's more, (Awen \& Hanan, 2013) featured the intricacy of the assessment framework; ineffective costs; defilement in the duty organization, and abuse of expense cash as a portion of the determinants that prompted an enemy of expense culture in Pakistan.

As can be seen from the writing, around the world, much accentuation has been put on the individual attributes of citizens and duty spirit and their relationship with tax avoidance. considers did by (Recardson, 2006), (Recardson, 2008), all have affected conduct perspectives, that is; all have connected tax avoidance to individual attributes, for example, age, sex, conjugal status, instruction, and even wellspring of pay. A few investigations, for example, the one did by (Philip \& Palda, 2004) have gone to the extraordinary of leading reviews to discover the conduct reactions alongside their discernments and individual attributes to gauge the affiliation with rates avoidance. Furthermore, these investigations have comprised assessment assurance and its relationship to duty avoidance.

In any instance, on account of the Republic of Pakistan, the investigations have measured macroeconomic factors and optional information used for ascertaining tax avoidance in the nation. There are a few investigations that have thought about some microeconomic factors and conduct reactions of respondents through overviews, for example, the one completed by (Ghafoor \& Hannan, 2014). In any case, these examinations have additionally restricted themselves to posing inquiries about political suppositions and have disregarded the connection between certain individual attributes and other social reactions of citizens and examples of tax avoidance of people.

The current investigation incorporates the dissemination of a poll to gather pragmatic data legitimately from citizens. Along these lines, certain markers of assessment resolve have been 
removed. Utilizing extraordinary econometric strategies, the relationship of these markers with tax avoidance has been built up. This investigation will be useful for officials and strategy creators to institute laws so they can improve charge assortment and receive the rewards of expanded income age that would then be able to be spent on the prosperity of the nation's residents and government. It can satisfy its commitments and offer open types of assistance to the majority successfully and proficiently.

\section{Methodology}

The record contains a cross-sectional overview concentrate in which essential information was gathered by conveying an organized survey to the chose respondents and their reactions were assumed the factors of intrigue. The exploration populace incorporates salaried people from the Identical Cities, that is; Rawalpindi and Islamabad district. The fundamental explanation behind considering the salaried class in the investigation is the way that the vast majority in the salaried class is presented to outsider revealing, which lessens their odds of being kept separate from the assessment net. Furthermore, it is compulsory as per the 2001 Revenue Tax Ordinance to subtract the duty at the foundation (F.B.R, 2012). These compensated staff true citizens.

An aggregate of 400 respondents was reached with the end goal of the investigation. Respondents were chosen by delineated arbitrary testing in which the populace was first defined into four areas and afterward 50 respondents from every segment in every city were chosen for the review. The divisions incorporated the private, open, NGO, and instruction parts, including college educating and managerial staff as it were.

The review instrument incorporated a Five-point like a gauge poll in which respondents were posed sure inquiries to quantify the impact of assessment confidence on tax avoidance as saw by respondents. As per (Luttmer \& Singhal, 2014) charge assurance incorporates:

1. Worry about blame and disgrace for non-installment of expenses

2. Worry for administrations gave by the national

3. Worry about others reimbursing a lot of the charges

4. Assents and penalties got for tax avoidance

The information collected through the overview was embedded into S.P.S.S v eighteen for the investigation phase. The investigation stage involved captivating regularities, rates, and Callous to contemplate the pattern of the reactions. Subsequently stage, the "t-test for one example" was taken to gauge the mean distinction of the test esteem and, thusly, rank the factors arranged by significance for the needy variable. The Cornbrash Alpha was additionally used to check the unwavering quality of the gathered information. Similar information was then broke down utilizing investigative procedures as referenced above and afterward contrasted and data acquired from magazine training, records, and level paper courses.

\section{Results and Discussion \\ Seen disgrace \& blame}

Disgrace alludes to a feeling where an individual feels corrupted or grasped when their demonstration of evil is uncovered, while blame is the inclination of disappointment that one feels after one turns into the shrewd that one accepts to be. Is dependable (Markell, 2000, p. 2178). Opinions of blame and disgrace alteration the expense consistence conduct of people (Eroded \& Feinting, 1993). At whatever point a separate assess their decision of duty avoidance, the disgrace influence is viewed as while doing the money-saving advantage examination (Kirchler, 2007) since disgrace and good expenses are emphatically connected with a person's duty consistence (Dulleck et al., 2016).

For the reasons for the investigation, two markers of blame and two of disgrace were taken during the study. Markers of disgrace included "are you apprehensive your name will be remembered for the FBR defaulter list" (DEFLST) and "do you think another person will report on the off chance that you avoid a lot of duties" (OTHREP) while shortcoming pointers included "he accepts that others should pay for the sum he dodges "(OTHRPY) and" he accepts that sidestepping charges is the best activity "(RGHTHG). The consequences of the overview of disgrace and blame are connected in Bench 1. The table remembers the defendants' reactions to the inquiries for disgrace and blame. The subtleties of the factors being referred to are joined as follows: 
Table 1: Explanation of Features of Disgrace and Fault

\begin{tabular}{llcclcccc}
\hline VAR & Gauge & $\begin{array}{c}\text { Replies } \\
\text { Share } \\
\text { Settle }\end{array}$ & Settle & Unbiased & Distress & $\begin{array}{c}\text { Share } \\
\text { Distress }\end{array}$ & $\begin{array}{c}\text { Aon't } \\
\text { Recognize }\end{array}$ & \\
\hline Disgrace & DEFLLST & 55 & 72 & 95 & 49 & 55 & 7 & 333 \\
& OTHTREP & 39 & 73 & 100 & 44 & 47 & 24 & 327 \\
Fault & OTHPRPY & 49 & 67 & 91 & 47 & 51 & 24 & 329 \\
& RGHTTHI & 158 & 101 & 47 & 11 & 12 & 5 & 334 \\
\hline
\end{tabular}

Disgrace Markers

As a portrayal of disgrace, respondents were approached to offer their input on the adequacy of their name being posted on the deficient rundown on the Central Panel of Income site. The reaction was requisite on a Five-point like a gauge, by 5 being entirely adequate and 1 noten in the slightest degree satisfactory. Most of $39 \%$ of defendants remained on the worthiness side of the bench, while just $31.8 \%$ had sentiments that demoralize the demonstration. The vast majority of the respondents who acquired $28.4 \%$ or 94 of the complete example size chosen choice 3, which implies that they indicated a lack of bias to the inquiry. The callous of 3.10 additionally demonstrates the equivalent. The reaction to the inquiry is set in Table 2 .

Thus, the 2nd inquiry concerning over again it was worthy to the defendant for another person to report their tax avoidance additionally created comparative outcomes. A vast greater part of $30.7 \%$ or 101 respondents chose choice 3 , in this manner staying impartial while the reactions stayed one-sided for the inquiry posed. A normal score of 2.8 likewise indicated that respondents were additionally unbiased to the subsequent inquiry.

\section{Table 2: Dread of tag in Nonpayers' List}

\begin{tabular}{llllll}
\hline S No. & Gauge & Reply & Incidence & $\%$ & Callous \\
\hline 1. & Do u panic that your label will be & 4 & 55 & 16.8 & $2.0+1.0$ \# \\
& $\begin{array}{l}\text { involved in the nonpayers' list } \\
\text { for non- payment of taxes? }\end{array}$ & 3 & 74 & 22.2 & 3.0 \\
& 2 & 91 & 28.1 & \\
(DEFLLST) & 1 & 49 & 14.6 & \\
& & 0 & 55 & 16.4 & \\
& & Don't know & 07 & 1.9 & \\
& & Total & $\mathbf{3 3 1 . 0 0}$ & $\mathbf{1 0 0 . 0 0}$ & \\
\hline
\end{tabular}

This particular propensity to impartiality can be credited to the way that it is hard to acquire exact responses to questions, for example, tax avoidance. Individuals frequently attempt to shroud their genuine answers and offer one-sided responses. (Schneider, 2003). In any case, the overview shows that individuals didn't acknowledge the disgrace factor (as dictated by the responses to the two inquiries posed). It is likewise appropriate to refer to here that Pak has an exceptionally lowest assessment to-G.D.P proportion of fair $13.4 \%$ of G.D.P, though the duty hole is $9.9 \%$, creation an aggregate of Pkr. 3.3 billion (Hasan, 2017). This demonstrates a great ethos of duty avoidance in the nation. Furthermore, the discoveries are likewise as per (Johns Cullies, 2011) and (Alams, 2011) who attest singular conduct of expense consistency is formed by the predominantly accepted practices in the public arena.

\section{Blame Markers}

The other variable "Blame" was additionally estimated with the assistance of two pointers, in particular; is it worthy for others to pay a lot of the assessments on the off chance that you sidestep? What's more, is it right to avoid charges? The responses to the two inquiries are appended beneath in Table 4:

\begin{tabular}{|c|c|c|c|c|c|}
\hline S No. & Gauge & Reply & Incidence & $\%$ & Callous \\
\hline \multirow[t]{7}{*}{2.} & \multirow{7}{*}{$\begin{array}{l}\text { Do you reflect it satisfactory } \\
\text { if somebody info your taxes } \\
\text { elusion to the specialists? } \\
\text { (OTHRREP) }\end{array}$} & 4 & 37 & 11.6 & $1.4+$ \\
\hline & & 3 & 73 & 21.8 & $1.4 \#$ \\
\hline & & 2 & 198 & 30.4 & 2.8 \\
\hline & & 1 & 46 & 13.8 & \\
\hline & & 0 & 49 & 14.7 & \\
\hline & & Don't know & 26 & 7.7 & \\
\hline & & Total & 329.00 & $100 .$. & \\
\hline
\end{tabular}


Table 3: Dread of somebody info Elusion

Table 4: Dread of somebody info Evasion

\begin{tabular}{clllll}
\hline S No. & \multicolumn{1}{c}{ Gauge } & Reply & Incidence & & \multicolumn{1}{c}{ Callous } \\
\hline 1. & In your view, is it satisfactory that 4 & 80 & 24.6 & $1.4+1.4$ \# 2.4 \\
somebody else stands the load of 3 & 77 & 23.1 & \\
taxes delusion on your part? & 2 & 59 & 18.6 & \\
(OTHRRPY) & 1 & 49 & 14.7 & \\
& 0 & 37 & 11.1 & \\
& Don't know & 26 & 7.7 & \\
& Total & $\mathbf{3 2 8 . 0 0}$ & $\mathbf{1 0 0 . 0 0}$ & \\
\hline
\end{tabular}

It is clear from the table that the outright greater part of respondents is in the scope of difference on the scale. As per the figures, an aggregate of $24.7 \%$ firmly deviated, while another $23.2 \%$ couldn't help contradicting the explanation of whether it was worthy to move their taxation rate to others through tax avoidance. The level of defendants cascades as the bench changes from the difference lateral to the understanding side. This is obvious from the way that solitary $7.6 \%$ completely concurred with the announcement. Even though the callous of 2.5 falls to some degree nearby the nonpartisan adjacent, it despite everything displays a proclivity towards the differing lateral of the bench.

The 2nd marker of blame, to some degree more straightforward, had a more grounded propensity towards the side of the contradiction. Practically $50 \%$ of the respondents who made practically $48 \%$ of the respondents unequivocally couldn't help contradicting the explanation whether it was right to avoid charges, while another $30.6 \%$ firmly couldn't help contradicting the announcement. Just about $21 \%$ of the defendants were in the staying 03 focuses on the Like gauge. A more grounded slant appears with the callous of 1.9 , so the announcement is dismissed completely. The responses to the inquiries concerning blame are connected in benches 4 and 5 .

Table 5: Pointers of Fault

\begin{tabular}{lllllll}
\hline S No. Gauge & & Reply & & Incidence & Callous \\
\hline 2. & Do you reason it is the correct 4 & 10 & 3.2 & $1.4+0.4$ \# 1.8 \\
& thing to & escape & tolls? 3 & 13 & 3.7 & \\
& (RGHHTHG) & 2 & 43 & 13.5 & 30.6 \\
\\
\end{tabular}

There is a diminishing pattern as we move towards the agreeableness side of the two markers, as appeared in Table 5 above. The outcome is predictable with an investigation (Baluster, Stilwell, \& Hitherto, 1995) expresses individuals accept activities' determination over-burden others, or once they imagine activities would-be observed downward on by others, individuals attempt to change conduct to is in accordance accept is acknowledged (p. 246).

What's more, the writing likewise proposes that religion additionally affects the assessment shirking conduct of people (Murtuza \& Ghazenfar, 1997) and (McGe, 1998) consume set up a connection among the morals of duty avoidance and Islamic \& They consume guaranteed that Islam's trains them decent residents and monitor the legislature nation. Nonetheless, as per (Bank, McGee, \& Yüzbaş1, 2015) Muslims should carefully keep charge rules when the nation is observing Islamic laws.

On account of the Republic of Pakistan, the constituent's express that Islamic-Pakistan is the Islamic Republic and all rules will be complete considering Shariah, consequently, observing the assessment decrees in Pakistan is the duty of all residents nation.

\section{Faith in the Administration}

Faith is the desire another individual's conduct won't adversely influence one's advantages (Paxton \& Smiths', 2007). Faith in this examination alludes reaction persons' duty avoidance conduct to the impression of the administrations gave by the state. Trust in government is legitimately connected to residents' consistent practices, including their choices to follow charge guidelines (Levi \& Stoker, 2000). If citizens believe in the administration and see that the legislature is working to their greatest advantage, they will select expense consistency regardless of whether avoidance has been a superior 
alternative (Levis, 1997). As per (Alam \& Toggle, 2003) it is an optimistic connection between faith in administration and assembly \& the expense consistence conduct of people. It implies deluding the legislature, particularly through tax avoidance, is less legitimate in nations where the degree of trust in the administration is higher, and the other way around.

To gauge trust in the administration, two pointers have been taken, right off the bat, fulfillment with the administrations gave by the legislature. The inquiry being posed in such manner to the federations, do you reason the duties remunerated are being used to offer sufficient types of assistance by the legislature to its residents? The

\section{Table 6: Discernment about use of taxes budget}

Subsequent marker to quantify trust included getting some information about their impression of debasement. The inquiry that was posed was how much you think your expense cash is being utilized

\begin{tabular}{lllll}
\hline S No & \multicolumn{1}{c}{ Gauge } & Incidence & $\%$ & \multicolumn{1}{c}{ Callous } \\
\hline 1. & Do you reason that tax elusion is Sturdily settle & 7 & 2.4 & $3.00+1.12$ \# \\
more when people observe duties Settle & 24 & 7.2 & 4.12 \\
paid are NOT being used to Impartial & 31 & 10.2 & \\
deliver for the vital public Distress & 106 & 32.5 & \\
facilities for the residents? & Strongly Distress & 153 & 46.10 & 0.7 \\
& Don't know & 3 & $\mathbf{1 0 0 . 0 0}$ \\
\hline
\end{tabular}

to line the pouches of legislators and authorities. The reactions are introduced in Tables 6 and 7.

\begin{tabular}{|c|c|c|c|c|}
\hline S No & Gauge & Incidence & $\%$ & Callous \\
\hline \multirow[t]{7}{*}{$\overline{1 .}$} & \multirow{4}{*}{$\begin{array}{l}\text { Do you decide that persons don't Strongly settle } \\
\text { pay tolls since the tax cash is Settle } \\
\text { being recycled to plug up the Impartial } \\
\text { pouches of officials and } \\
\text { bureaucrats? }\end{array}$} & 208 & 62.5 & \multirow{7}{*}{$\begin{array}{l}1.0+0.5 \\
\# 1.5\end{array}$} \\
\hline & & 86 & 25.5 & \\
\hline & & 23 & 7.5 & \\
\hline & & 6 & 1.6 & \\
\hline & Strongly Upset & 8 & 2.2 & \\
\hline & Don't know & 3 & 0.7 & \\
\hline & TOTAL & 334.00 & 100.00 & \\
\hline
\end{tabular}

The table above shows an expanding pattern as it moves to the different side of the announcement. Practically $50 \%$ of the example size, $46.9 \%$, emphatically couldn't help contradicting the case that their duty cash was being utilized for open administrations gave by the legislature. The mean of 4.12 oddballs the case about the arrangement of open administrations by the legislature.

The subsequent marker has created similar outcomes. An outright greater part of $62.6 \%$ completely concurred with the announcement, while around a quarter concurred, yet less significantly. The callous of 1.6 demonstrates that the reaction design is slanted concerning the understanding horizontally, so the reaction pattern acknowledges announcement. The discoveries in accordance way that is a solid chance that lawmakers and open authorities will eat open cash for their stakes, there is less left to spend on open administrations, prompting a more noteworthy tendency of residents concerning tax avoidance. (Litinaas \& Palivose, 2014).

In Pakistan, defilement is happening the ascent. As indicated by Transparency International, Pakistan positioned 117th on the Corruption Perception Index with 32nd in two continuous years in 2016 and 2017. Defilement in Pakistan is extraordinary to the point that the nation's acting Prime Minister was blamed for debasement and expelled from office. From his post in 2017 after charges were demonstrated against him and his nearby partners. This prompted a more prominent view of debasement in the brains of residents that brought down the degree of trust in the administration in the psyches of the majority. Moreover, there has been a developing hole between the administration and the residents of the nation with regards to the arrangement of open administrations. As indicated by a report distributed through the (P.P.A.F) in 2016-17, there is an enormous hole among the interest arrangement of open administrations nation, particularly for helpless populace a long way from the fundamental urban communities (Naveed, 2017).

Discernment that others settle charges 
Accepted practices and culture affect tax avoidance propensities for its residents (Cullis, Joanes, and Slovioa, 2012). People follow the guidelines when they know that consistency is accepted practice (Alm, 2012). At the point when an individual watches unscrupulous conduct in their neighborhood, their impression of normal practices concerning trustworthiness and morals changes (Ginos, Ayals, \& Arelys, 2008). The writing displays citizens restrictively keep guidelines (eg, charge rules) up to where others in the public eye are responsible likewise (Fraey \& Torglers, 2008; Traxlar, 2011). In this way, the observation about the assessment consistence conduct in the group of friends directly affects the duty consistence conduct of a person.

To quantify the effect of the recognition that others pay a lot of assessments on tax avoidance, the inquiry posed to remember 'As you would see it, do you think others in your neighborhood are settling charges?' The response inquiry is added in Bench 08. By way this apparent from the organized statistics, most of the defendants are the locale of the scale from impartial to decently concur. As indicated by measurements, $30 \%$ of respondents stayed nonpartisan to the announcement, while $26.4 \%$ firmly concurred with the announcement. The mean score of 2.7 additionally demonstrates a similar district of the worthiness of the case. In this manner, the overview doesn't unequivocally uphold the case.

Table 8: Observation about others evasion tariffs

\begin{tabular}{clcccc}
\hline S No & Gauge & Reply & Incidence & $\%$ & Callous \\
\hline 1. & Do you reason tax elusion Strongly Settle & 44 & 13.5 & $2.0+0.7$ \# \\
& surges when others in your Settle & 88 & 26.5 & 2.7 \\
& locality are escaping their tolls? Impartial & 96 & 30.0 & \\
& Upset & 37 & 10.7 & 14.3 \\
\\
\end{tabular}

\begin{tabular}{cccccc}
\hline \multicolumn{2}{l}{ Table 9: Observation about equal of Forfeits } & & & \\
\hline S No & Gauge & Reply & Incidence & $\%$ & Callous \\
\hline 1. & $\begin{array}{l}\text { Do you think forfeits are passable Strongly Settle } \\
\text { plenty on taxes elusion in the Settle }\end{array}$ & 65 & 19.7 & \\
republic? & Impartial & 701 & 30.6 & $2.00+0.52$ \\
& Upset & 38 & 24.0 & $\# 2.52$ \\
& Strongly Upset & 38 & 11.0 & \\
& Don't Know & 13 & 3.0 & \\
& TOTAL & $\mathbf{3 3 4 . 0 0}$ & $\mathbf{1 0 0 . 0 0}$ & \\
\hline
\end{tabular}

\section{Punishments for Tax Avoidance}

Punishments and fines have been appeared to significantly affect charge consistency practices. Be that as it may, an enormous fine for tax avoidance has been demonstrated to be more negative to burden consistence contrasted with a high likelihood of existence gotten (Chrysene, 1981) and (Nourzads \& Crana, 1985). Nonetheless, an examination by (Obid, 2004) inferred that reviewing likelihood and authorizations significantly affect individuals' assessment consistence conduct up to the moment that the administration utilizes compelling apparatuses. While punishments and the probability of being gotten assist shape with peopling's consistence conduct, these impacts fluctuate dependent on segment factors, for example, the citizen's sexual orientation, age, and even word related status (Devos, 2008). This study likewise confirmed the effect of apparent assents on individuals' tax avoidance conduct. The outcomes have appeared in Table 9.

The reaction demonstrates that a great many people concurred with the explanation that the punishments were sufficient enough for charge dodgers. An aggregate of 102 respondents, causing $30.5 \%$ to concur, while $19.8 \%$ completely concur with the announcement, making a sum of practically half or a large portion of the size of shows it on the concur lateral of the bench. The difference remained just $20.4 \%$ of the absolute reaction degree, while-as $25 \%$ stayed impartial. The normal number of 2.6 shows a lean concerning the side of contradiction (even though not unequivocally concur).

As indicated by Section 183 of the Income Tax Ordinance, the 20012 fine for rebelliousness with the annual expense is 5\% in the main break, an extra $20 \%$ in the second, an extra 25 percent in 
the third, and $50 \%$ on the fourth time on the measure of charges dodged. Notwithstanding, the punishment can't surpass $100 \%$ of the aggregate sum. This circumstance contrasted with adjacent Indian is a little alteration, punishment for non-installment of charges can prompt up-to $350 \%$ assessments evaded, the US, the Internal Revenue Service (IRS) forces punishments of up to $25 \%$ every month on sidestepped charges.

Having seen the authorizations circumstance of the two nations, the examination shows that the punishment for tax avoidance in Pakistan is great, yet noten to that degree. Circumstantially, review consequences show equivalent, as a maximum of defendants stayed on the concurring lateral of the gauge, even though not looking for solid understanding.

Consistency Test

Cronbach's Alpha Table

\begin{tabular}{cc}
\hline Cronbach's Alpha & No of Objects \\
\hline .600 & 10 \\
\hline
\end{tabular}

Grade of .600 displays that information is solid since anything more noteworthy than 0.50 implies that the information is dependable.

Test-T

T-test measurements were additionally determined to square the implication of the information. Outcomes are organized in Bench 10.

The aftereffects (t-test) demonstrated that 03 of the 8 factors have callous qualities less than the exam estimation of 2.50. These-major factors incorporate the view of the utilization of assessment cash to line the pockets of authorities and lawmakers and the two factors of shortcoming. Also, the impression of the degree of punishments for tax avoidance doesn't a lot of trouble tax avoidance conduct either. While the remainder of the factors that incorporate both the disgrace markers and the view of other people who pay sincerely have more effect on tax avoidance conduct. The impression of the utilization of duty cash has the best effect on tax avoidance, as found in Table 10. It is relevant to refer to here that all the outcomes are noteworthy at the $1 \%$ level of essentialness.

Table 10: T-Test

\begin{tabular}{lllll}
\hline VAR & \multicolumn{2}{l}{ Test Value } \\
t-values & $\mathbf{2 . 5}$ & Callous & P-Values & Callous \\
& & & & Variance \\
\hline Use of currency & -20.076 & 4.13 & 00.0000 & 1.63 \\
Substantial bags & -30.753 & 1.51 & 00.0000 & -01 \\
Name in nonpayer list & -1.902 & 3.01 & 00.0000 & 0.6 \\
Somebody will statement & -3.175 & 2.81 & 00.0000 & 0.2 \\
Separate disbursing reliably & -3.846 & 2.80 & 00.0000 & 0.1 \\
Liability RIGHTT-THINGSS & -20.071 & 01.70 & 00.0000 & -00.8 \\
Another will reimbursement more & -03.252 & 02.50 & 00.0001 & -00.2 \\
Consequence on elusion & -06.573 & 02.40 & 00.0000 & 00.03 \\
\hline All &
\end{tabular}

All standards are important at $1 \%$ equal to important

Party-political mediation for charge consistence

Albeit abundant effort has been done in the arena of duty avoidance \& consistency, lesser commitment has been complete in the writing that centers proceeding the job of governmental issues informing the consistent conduct of people. Notwithstanding, the writing identified with the open decision has tended to the issue of the commitment of government officials and the decision lesson informing and regulatory the budget (Bene-Porathes, 1974), (MacCrakans, 1976) and (Tuftets, 1977). An examination did by (MacRae, 1977) presumed that legislators have a job in molding resident conduct as a device to get political courtesies by controlling the financial circumstance during discretionary ages. This design is recognized as the constituent series of methods and is a piece of the political business cycle hypothesis. As per (More, 2014), the legislature concentrates just on the citizen portion that it considers produces the most income.

One of the apparatuses to influence the economy by the nation's decision first class incorporates affecting the organization and assessment structure (Kim, 2008). Thusly, the job of governmental issues in molding tax avoidance conduct in a general public can't be precluded. Besides, as found in the past conversation, a sum of four determinants of expense assurance that end up being noteworthy supporters of tax avoidance were examined so distantly in the archive, and of the 04 factors, 03 are legitimately identified by legislature incorporate the use of duty cash; term to be 
remembered for the rundown of nonpayers, and somebody will record the revenue to the administration. Notwithstanding, the fourth-factor "others" pay a lot of duties sincerely "be able likewise to be ascribed job the legislature, so governmental issues have a significant task to carry out in such manner.

The overview results show that the view of the utilization of assessment cash assumes a significant job in the expense consistence conduct of citizens. The administration should concentrate on offering open types of assistance to the majority in return for them agreeing to the nation's duty laws. To pick up the trust of governments, citizens must know where their assessments are being utilized. One of the strategies is the home loan (Seely, 2011). This cycle includes designating a bit of citizen cash to specific undertakings or permits citizens to utilize their assessment cash in the zone of their advantage (Brockmann, Genschel, \& Seelkopf, 2015). One model, referred to by Brockman, is that of Spain's, where-as citizens remained permitted to use part of-their assessment cash concerning to a noble cause for the congregation, though the other model is that of Japan's, where-as citizens can pay part of the duty. The annual assessment for the improvement of any provincial property. Nation zone.

The other variable that influences charge consistency is the component of disgrace. One of the techniques to control tax avoidance is to genuinely contact charge dodgers. An examination completed by (Coricelli, Joffily, Montmarquette, \& Villeval, 2010) proposed that open notice of the names of delinquent citizens directly affects individuals' assessment consistence conduct. Hence, the Central Panel of Income must distribute the tags of assessment nonpayers on its site or paper and web-based broadcasting to misuse component of disgrace and guarantee charge consistence. Notwithstanding, care must be taken that dodgers are reintegrated instead of disparaged for a more drawn out timeframe because criticizing or trashing a person for being a duty dodger has been appeared to subvert governments' expense consistence endeavors. (Coricelli, Rusconi, \& Villeval, 2014).

It is likewise relevant to refer to here, even though assents and fines do assume a job in molding citizens' consistent conduct, however, such arrangements are not as huge as the way of life (recognition that others conform to burden laws) of consistence. Feeder (Guerra \& Harrington, 2017). Even though the administration has the power to force fines and punishments, and even conclude whether to authorize consistence by propelling the cycle or rewards or enacting the component of disgrace as referenced in the past passages. Be that as it may, it isn't workable for governments to straightforwardly apply an ethos of consistency. Altogether the administration essentials are to build up values that support tax avoidance.

\section{Conclusion}

Since the overhead conversation tends to be reasoned an aggregate of 06 factors supported and chosen as potential elements of tax avoidance. The survey remained conveyed to plaid the impression of the defendants on these chose factors and their apparent impact on duty avoidance. Outcomes show its factors of blame, defilement, and saw endorsement didn't have a lot of effect on tax avoidance, while the factors that contain the utilization of assessment cash, disgrace, and the recognition that others in the region pay their duties greatly affected tax avoidance, separately. Considering the review, it is suggested that strategy producers and assessment specialists put a great deal of spotlight on causing individuals to understand that their charges are being utilized proficiently and adequately. Political intercession in such a manner has been proposed in the report. A few endeavors in such a manner incorporate designating some portion of the expense to a particular reason and in any event, heading off to the region of the citizen's decision. Furthermore, distributing the names of delinquent citizens will likewise improve charge consistency. Essentially, making a situation for government consistency will likewise urge individuals to agree to burden laws. This thus would make a culture of assessment consistency and individuals will be more agreeable because of social impacts.

\section{References}

Allingham, M. \& Sadmo, A. (1972). Income Tax Evasion: A Theoretical Analysis. Journal of Public Economics, 1, 323-338.

Boylan, S. \& Sprinkle, G. (2001). Experimental Evidence on the Relation between Tax Rates and Compliance: The Effect of Earned vs. Endowed Income. Journal of the American Taxation Association, 23(1), 75-90. 
Fisher, R., Goddeeris, J. \& Young, J. (1989). Participation in Tax Amnesties: The Individual Income Tax. National Tax Journal, 42(2), 15-27.

Lefebvre, M., Pestieau, P., Riedl, A. \& Villeval, M. C. (2011). Tax Evasion, Welfare Fraud, and the Broken Windows Effect: An Experiment in Belgium, France, and the Netherlands. IZA Discussion Paper No. 5609.

Orewa, G. O. (1957). Taxation in Western Nigeria. London Oxford University Press.

Pommerehne, W., Hart, A. \& Frey, B. (1994). Tax Morale, Tax Evasion, and the Choice of Policy Instruments in Different Political Systems. Public Finance, 49, 52-69.

Schneider, F. \& Enste, H. D. (2000). Shadow Economies around the World - Size, Causes, and Consequences. IMF Working Papers 00/26.

Skinner, J. \& Slemrod, J. (1985). An Economic Perspective on Tax Evasion. National Tax Journal, 38, 345- 353. Srinivasan, T. (1973). Tax Evasion: A Model. Journal of Public Economics, 2(3), 339-346.

Uadiale, O. M., Fagbemi, T. O. \& Ogunleye, J. O. (2010). An Empirical Study of the Relationship between Culture and Personal Income Tax Evasion in Nigeria. European Journal of Economics, Finance and Administrative Sciences, 20, 116-126.

Warner, S. (1965). Randomized response: a survey technique for eliminating evasive answer bias. Journal of the American Statistical Association, 60, 63-69. 